\title{
Towards a Deeper Understanding of Meaningful Use in
}

\section{Electronic Health Records}

\begin{abstract}
Objective: The purpose of this paper is to identify and analyse the US Health Sector concept of the

"Meaningful Use" of Electronic Health Records (EHR's) based on the wide diversity of discourses in the published literature. Meaningful Use is defined the "use of digital medical and health records to improve quality, safety, and efficiency of patient health information

Methods: Herman Dooyeweerd's philosophical suite of aspects was the chosen research tool used to analyse seminal papers concerning the Meaningful Use of EHRs. The methodology included identification of the criteria for choosing the papers; application of the criteria to the literature and then selection of the papers, and finally the application of Dooyeweerd's aspects to the papers in order to analyse and classify the motivations of the authors.
\end{abstract}

Results: As a result of the aspectual analysis of the relevant texts in the seminal papers, two aspects were identified, one as primary and another one as secondary. In addition, the analytic aspect was repeated twice as the primary aspect. Although there were a number of papers distinctively centred on different aspects, overlaps and similarities were also clearly identified.

Discussion: Dooyeweerd's philosophy is useful in helping to affirm the factors that are important to the authors of the seminal papers and the philosophy helps us to accommodate this diversity in a unique way, therefore enhancing our understanding of approaches in the area.

1

This is the peer reviewed version of the following article: JONEIDY, S. AND BURKE, M. (2018), TOWARDS A DEEPER UNDERSTANDING OF MEANINGFUL USE IN ELECTRONIC HEALTH RECORDS. HEALTH INFO LIBR J., which has been published in final form at https://doi.org/10.1111/hir.12233. This article may be used for non-commercial purposes in accordance with Wiley Terms and Conditions for Use of Self-Archived Versions. 
Conclusion: By employing the lens of Dooyeweerd's aspects the study enhances the understanding of diversity in one discipline and could potentially provide a new system for the classification of diversity within other related disciplines.

\section{Key Messages}

- Aspectual text-analysis should be used as a different method for analysing texts, especially by those who are interested in seeking meaning in the Health literature.

- It is important to affirm the diversity in the growing field of Meaningful Use EHRs by exploring the motivation of researchers.

- Findings show that meaningfulness can be used as a basis in order to identify and systematise the diversity of authors' motivations in a field of research.

\section{Keywords}

Diversity, Dooyeweerd, Aspects, Meaningful Use, EHRs

\section{Background}

Most U.S. health care services now employ some level of Electronic Health Records (EHRs), i.e. a computer-based information system to record patient details. The health care industry in the U.S. has invested heavily in promoting what is referred to as the "meaningful use" of information systems by encouraging the uptake and use of EHRs. The reason for the promotion is to ensure that health related

2

This is the peer reviewed version of the following article: JONEIDY, S. AND BURKE, M. (2018), TOWARDS A DEEPER UNDERSTANDING OF MEANINGFUL USE IN ELECTRONIC HEALTH RECORDS. HEALTH INFO LIBR J., which has been published in final form at https://doi.org/10.1111/hir.12233. This article may be used for non-commercial purposes in accordance with Wiley Terms and Conditions for Use of Self-Archived Versions. 
technologies are used in a careful and 'meaningful' way by all staff. Meaningful Use of EHRs is now an important field of research, and is defined as "using digital medical and health records to improve quality, safety, efficiency, and reduce health disparities, engage patients and family improve care coordination and population and public heath, and maintain privacy and security of patient health information.”(Cox \& Srinivasan, 2017) The proliferation of papers centered on the "Meaningful Use of EHRs attests to the emergence of numerous observations and understandings from a vast group of stakeholders such as doctors, academics and policy makers. This has shaped a fragmented and disjointed field of study. Though the field of research has proliferated with an increasing number of impressive research papers on Meaningful Use in EHRs, addressing a wider spectrum to give a more holistic interpretation is necessary to enhance our understanding.

The aim of this paper is to identify and grasp the concepts of Meaningful Use in EHRs based on the diversity of discourses surrounding the Meaningful Use of Electronic Health Records in the U.S. health sector. The study starts by applying Herman Dooyeweerd's (Dooyeweerd, 1955) conceptual tool known as his of "Suite of Aspects", which are built on different spheres of meaning in the cosmos. By applying Dooyeweerd's suite of aspects, we are able to provide a rich picture of Human Activity Systems (Mirijamdotter \&BergvallKåreborn, 2006 ). Basden uses Dooyeweerd's aspects and views disciplines in terms of what is meaningful to those who work within them (Basden,2010). The suite of aspects helps us to discover what is denoted as "meaningful" in the eye of researchers who are moving this field of study forward.

The organization of the paper is as follows. First, the paper sets the context of study by introducing our understanding of previous research on Meaningful Use of EHRs. Second, a discussion is presented regarding the approaches that have been adopted so far, in understanding the range of diversity of the relevant discourses. Third, a philosophical approach is suggested that could lead towards the creation of a new insight which would assist in our understanding of the diversity of these discourses. The research 3

This is the peer reviewed version of the following article: JONEIDY, S. AND BURKE, M. (2018), TOWARDS A DEEPER UNDERSTANDING OF MEANINGFUL USE IN ELECTRONIC HEALTH RECORDS. HEALTH INFO LIBR J., which has been published in final form at https://doi.org/10.1111/hir.12233. This article may be used for non-commercial purposes in accordance with Wiley Terms and Conditions for Use of Self-Archived Versions. 
methodology forms the next section which consists of the examination of pertinent seminal papers that have moved forward the field of Meaningful Use of EHRs. Having identified specific papers, Dooyeweerd's suite of aspects is then used to analyse these texts. The detailed findings are considered and thoughts are offered regarding the benefits of Dooyeweerd's philosophy in interpreting Meaningful Use in EHRs.

\section{Diversity of research problems in the field of Meaningful Use of EHRs}

The section reviews the ongoing discourses on "Meaningful Use" in the US health sector.

According to Jha et al consensus shows that health information technology is safe, efficient, and delivers higher-quality care (Jha \& DesRoches,2009). Despite these benefits, the pervasiveness of adopting electronic health records in U.S. hospitals is still very low (Morton \& Wiedenbeck ,2010). Other studies highlighted the slow pace of absorption amongst small and independent practices and suggested acceleration in pace is a must, if professionals want to adhere to the HITECH Act (DesRoches, Worzala, Joshi,Kralovec\&Jha,2012; Hsiao,Decker,Hing,Sisk,2012; Franczak et al.,2014; Adler-Milstein et al.,2014; Wolf ,Harvell \&Jha ,2012; Walker\&Diana 2016). In line with this, Jha reported the first step in adoption of health information technology should be the encouragement of physicians to apply and use EHR's (Jha, 2012)

To fulfil the aims of Meaningful Use, understanding the use of EHRs is vital in order to encourage use and adoption across all health care sectors in the future (Lanham,Leykum\&McDaniel ,2011). As EHRs encompass a range of diverse categories and levels of use, a more thorough investigation of EHRs functions is required (Hogan\&Kissam ,2010). In order to use EHRs' effectively certain requirements are needed such as - numerous organizational and environment facilitators; strong support systems; the presence of system attributes and identification of selective users (Holden \& Karsh ,2010)

4

This is the peer reviewed version of the following article: JONEIDY, S. AND BURKE, M. (2018), TOWARDS A DEEPER UNDERSTANDING OF MEANINGFUL USE IN ELECTRONIC HEALTH RECORDS. HEALTH INFO LIBR J., which has been published in final form at https://doi.org/10.1111/hir.12233. This article may be used for non-commercial purposes in accordance with Wiley Terms and Conditions for Use of Self-Archived Versions. 
Poon et al. on the other hand, conducted a comparison study of the use of a standard EHR and the use of EHR with the "quality of care" feature. This study spurred further studies on the use of features (Poon et al.,2010). Spyropoulos et al. (2015) agrees with Jha's findings and suggests that, in order to optimize therapy, specialized features are necessary and are yet to be incorporated in EHRs (Jha,2012). Conversely, there is mixed evidence on the correlation between specialized features and what produces optimum therapy and outputs. For example, Sinsky et al. found that doctors preferred to spend time with patients to optimize therapy rather than to spend their time on more administrative matters such as evaluating web site usage (Sinsky et al.,2016)

Krist and Woolf (2011) confirm Spyropoulos et al. (2015) findings that EHRs requires an increase in functionality to fully engage patients. EHRs' functionalities work well when they are designed around the needs of the patient i.e. patient driven. However, Halamka (2010); Raltson et al.(2010) pointed out that patient-provider communication has been given less emphasis in the areas of patients' usage of EHRs (Spyropoulos et al. ,2015) and patient satisfaction (Kazley,Diana,Ford\&Menachemi ,2012) despite the huge investment in this area.

Ralston et al. (2010) highlighted the need to measure patients' experiences in understanding Meaningful Use. Ahern et al. (2011) designed a Meaningful Use framework of safety, healthcare quality and population of health. In line with that, Ajami and Bagheri-Tadi (2013) listed barriers in adopting EHRs as perceived by physicians. One barrier that seems to tie up with Jha's (2012) finding is the low adoption rate associated with resistance from physicians (Bowens,Frye\&Jones ,2010). However, Harle et al. (2014) suggested that as medical students use EHRs whilst training, physicians will need to work with EHRs as more technologysavvy clinicians enter the field.

The study undertaken by Lanham, Leykum, and McDaniel in 2012 explored the links between "within-

5

This is the peer reviewed version of the following article: JONEIDY, S. AND BURKE, M. (2018), TOWARDS A DEEPER UNDERSTANDING OF MEANINGFUL USE IN ELECTRONIC HEALTH RECORDS. HEALTH INFO LIBR J., which has been published in final form at https://doi.org/10.1111/hir.12233. This article may be used for non-commercial purposes in accordance with Wiley Terms and Conditions for Use of Self-Archived Versions. 
practice communication patterns and practice-level EHR use patterns in order to "provide a unique perspective for exploring the issue of standardization in EHR use” (Lanham,Leykum\&McDaniel ,2012).

This study used a qualitative approach across a range of sites within the same health organization. Semi structured interviews plus location field notes provided detailed results. These results showed that there was a clear relationship between practice-level EHR use patterns. Where communication was disjointed and used a variety of different formats EHR use was labelled as "heterogeneous." In locations where the opposite types of communication were prevalent (very organized and systematic) the result was that EHR use could be described as "homogeneous." Interestingly, an additional result was also reported that "practices that had achieved standardized EHR use (uniformly high EHR use across all users) exhibited high levels of mindfulness and respectful interaction, whereas practices that were furthest from achieving standardized EHR use exhibited low levels of mindfulness and respectful interaction" (Lanham,Leykum\&McDaniel ,2012).

The authors concluded that "understanding the relationship between communication patterns and EHR use may provide key lessons for implementing EHRs - in ways that promote more effective and meaningful patterns of EHR, yet use without restricting customizations needed to accommodate differences between individual physicians and physician practices."

The limitations of the study included the small number of sites all within one overarching organization and the fact that the study did not consider the organizational levels of the members.

An earlier study, conducted in 2010 by Bates and Bitton considered the need to improve "efficiency, quality, and safety" in patient-centred medical homes. The research considered evidence of the performance of these types of homes and reported on seven major areas which (then) needed EHR innovations. These areas were identified as "telehealth; measurement of quality and efficiency; care transitions; personal health

This is the peer reviewed version of the following article: JONEIDY, S. AND BURKE, M. (2018), TOWARDS A DEEPER UNDERSTANDING OF MEANINGFUL USE IN ELECTRONIC HEALTH RECORDS. HEALTH INFO LIBR J., which has been published in final form at https://doi.org/10.1111/hir.12233. This article may be used for non-commercial purposes in accordance with Wiley Terms and Conditions for Use of Self-Archived Versions. 
records; registries; team care and clinical decision support for chronic diseases” (Bates\&Bitton ,2010).

In particular these authors comment that the "current meaningful use definitions do not (as yet) directly address medical homes".

The limitations of this study would seem to be simply in terms of needing further studies in the area in order to encourage funding. The authors suggest that funders such as the Agency for Healthcare Research and Quality should consider a range of areas as priority such as "delivering effective clinical decision support for major chronic conditions."

So far we have discovered diverse discussions on meaningful use in EHRs. Each discussion evolves around its own research problems and work amongst several discourses with possible overlaps. The discussion so far explores the diversity of discourses in the field of Meaningful Use of EHRs. The next section of the paper highlights a way for making helpful sense of this diversity.

\section{Attempts in Making Sense of Diversity}

Diversity of discourses in the Health-IT were highlighted in the previous research. There have been various attempts in accommodating the diversity of discourses. Boulus-Rødje research reviewed visionary discourses about the imagined potentialities of EHRs in major Canadian and American newspapers. The study categorized these discourses based on topic and portrayals of the EHRs. For example benefits (cost, efficiency, empowerment), comparisons (with other technologies, industries, countries), critiques (unfulfilled promises, lack of evidence), etc. This categorization provided an overview of the topics discussed, and how similar topics could be discussed in different ways across different articles. Boulus considers that these visionary discourses about the imagined potentialities of EHRs "bear strong generative power with the capacity to transcend time in such a way that future visions are presented as tangible and 7

This is the peer reviewed version of the following article: JONEIDY, S. AND BURKE, M. (2018), TOWARDS A DEEPER UNDERSTANDING OF MEANINGFUL USE IN ELECTRONIC HEALTH RECORDS. HEALTH INFO LIBR J., which has been published in final form at https://doi.org/10.1111/hir.12233. This article may be used for non-commercial purposes in accordance with Wiley Terms and Conditions for Use of Self-Archived Versions. 
accomplishable". While these visions are indeed powerful, they are far from corresponding to the reality on the ground whereby as many as $70 \%-80 \%$ of physicians are still using paper-based records (BoulusRødje ,2013). However, Boulus-Rødje offered the notion of 'imagined potentialities' to increase analytical sensitivity to the interplay between the material and discursive processes that are at play in shaping present and future healthcare technologies (Boulus-Rødje ,2013). Other EHR studies such as that undertaken by Meigs and Solomon's in 2016 reported findings that included the belief among physicians that EHR systems need to be more user-friendly and adaptable to individual clinic workflow preferences, and physician beliefs that the lack of interoperability among EHRs is a major barrier to Meaningful Use of the systems (Meigs\&Solomon ,2016).

Klecun focused on policy papers that transform health care in understanding the relationship between Patient-Centric Care (PCC) and the role of Information Technology (IT). The aim was to address the misalignment between health care policy visions and IT implementation. Whilst these papers offer interesting and useful perspectives these attempts do not specifically help us in making sense of the diversity of Meaningful Use discourses in the U.S. health sector (Klecun,2016). Indeed the study of literature in the area by Scott Kruse and Kristof et al. concluded that "Additionally, further research in the area of EHRs would likely profit from identifying key factors of achieving the current stages of Meaningful Use in an effective manner. This in particular would be most beneficial, as we believe that many healthcare institutions, as shown by the research, fail to achieve Meaningful Use as they have adopted an excessively basic EHR in order to meet the minimum standards for regulation under HITECH. This low-functioning EHR can actually negatively impact the time, effort and cost as opposed to streamlining processes, reducing error and reducing cost, which are the hallmarks of a high-functioning EHRs." (Kruse,Kristof,Jones,Mitchell\&Martinez,2016) There is then, clearly a need for further exploration in the area of diversity of Meaningful Use.

8

This is the peer reviewed version of the following article: JONEIDY, S. AND BURKE, M. (2018), TOWARDS A DEEPER UNDERSTANDING OF MEANINGFUL USE IN ELECTRONIC HEALTH RECORDS. HEALTH INFO LIBR J., which has been published in final form at https://doi.org/10.1111/hir.12233. This article may be used for non-commercial purposes in accordance with Wiley Terms and Conditions for Use of Self-Archived Versions. 
It is also interesting to study information systems theories surrounding the social and technical context of health care. For example, Chiasson and Davidson examined the publication of health information systems research (HISR) in seventeen Information Systems (IS) journals published since 1985. They looked at the interplay between the application of IS theory to a variety of healthcare contexts. They classified the articles using the following four categories to characterize each authors' strategy in terms of dealing theoretically with the healthcare setting: (i) IS only papers. These papers focus on defining new IS theory or testing and refining pre-existing IS theories; yet how the study's healthcare context might influence theoretical constructs, assumptions, or analysis was not explored, (ii) IS-healthcare papers. These primarily focus on developing or testing IS theories, with some consideration of general or specific institutional issues in healthcare settings that influence study findings; (iii) healthcare-IS papers which apply theories or concepts, to inform the analysis of the empirical findings, and explore contextual influences on IS/IT within the healthcare setting; and (iv) healthcare only papers which primarily describe healthcare technologies, systems, or implementation projects, with little consideration of IS theory (Chiasson \& Davidson ,2004).

Whilst all of these attempts add to the exploration of MU discourses in the U.S. health sector, there is still a need to make sense of diversity in this area. Benbasat and Weber in 1996 study on rethinking diversity in IS research is considered in this section as their study established the basic framework for researchers who aim to explore the cost and benefit of diversity in IS research (Benbasat \& Weber ,1996).

According to Benbasat and Weber three types of diversity are eminent in the IS research; 1) Diversity in the research problems 2) Diversity in the theoretical foundations and reference disciplines and 3) Diversity in the research methods. Benbasat and Weber focused primarily on theoretical diversity, because they believe that theories are the fundamental factor that shapes the course of a discipline. Moreover, they agree with Thomas Kuhn that researchers have difficulty viewing problems and phenomena in the world except through the lens of the theories they choose to employ. Though they provide a clear understanding of

9

This is the peer reviewed version of the following article: JONEIDY, S. AND BURKE, M. (2018), TOWARDS A DEEPER UNDERSTANDING OF MEANINGFUL USE IN ELECTRONIC HEALTH RECORDS. HEALTH INFO LIBR J., which has been published in final form at https://doi.org/10.1111/hir.12233. This article may be used for non-commercial purposes in accordance with Wiley Terms and Conditions for Use of Self-Archived Versions. 
diversity of reference discipline and research methods, their treatment of research problems is ambiguous. It is important to understand the diversity of research problems because different kinds of research problems affect and differentiate the discourses. The diversity of discourses around research problems emerges over time as new discourses are created

Vessey et al.'s study portrayed diversity as multi-dimensional, depending on the characteristic under examination. For example, they show in their research that the characteristics that are most diverse in the information systems journals examined from 1995 to 1999 are reference discipline, organizational topic, research method, and level of analysis (Vessey \& Ramesh,2002). Research approach, on the other hand, is much less diverse whereas topic is least diverse. Vessey et al. addressed the diversity in IS research by considering topics and by perusing text or key words (Vessey \& Ramesh,2002).

The literature regarding the Meaningful Use of EHRs' discourses revolves around different research problems and, the field, at the moment, seems unable to provide a clear explanation in the way in which diversity is handled by all the authors. This study attempts to view, through a philosophical lens, a new, fresh and distinctive insight to Meaningful Use in EHRs. So, whilst theses discourses are ongoing they are unable by themselves to provide a way of accommodating or categorizing this diversity. There is then, a need for a philosophical approach.

\section{Dooyeweerd's Philosophy}

Herman Dooyeweerd (1894-1977) studied the past 2500 years of western philosophy and provided an indepth critique of theoretical thinking. One of dominant Dooyeweerd's contributions is that everyone has some kind of ultimate commitment in their everyday life experience, including thinking and theoretical activity.

This is the peer reviewed version of the following article: JONEIDY, S. AND BURKE, $M$ (2018), TOWARDS A DEEPER UNDERSTANDING OF MEANINGFUL USE IN ELECTRONIC HEALTH RECORDS. HEALTH INFO LIBR J., which has been published in final form at https://doi.org/10.1111/hir.12233. This article may be used for non-commercial purposes in accordance with Wiley Terms and Conditions for Use of Self-Archived Versions. 
Dooyeweerd believed that everybody's thinking presupposes a religious ground-motive. Most people are unaware of the fact that underlying their thinking the ground-motives forces are at work (Diller,1990).Ground motives ('grondmotieven') are Dooyeweerd's term for the "spiritual driving force that acts as the absolutely central mainspring of human society"( Dooyeweerd,1979). Details of the groundmotives are beyond the scope of this paper. Of all the four ground-motives he identified, three of them are dualist, and provided a critique of them. It is only the Creation-Fall-Redemption (CFR) ground-motive that goes beyond dualism and can account for the diversity we experience around us, without ending up in fragmentation (Basden, 2017). (i.e. lack of coherence between the aspects).

The Diversity in creation, including everyday life experiences and thinking is well-introduced and explained by Dooyeweerd's theory of modal aspects. Dooyeweerd's aspects are beyond definitions. Dooyeweerd suggested that we can 'grasp' the meaning of each aspect better by intuition than by intellect or definition (Basden, 1997). Rather than expecting a perfect definition, the best approach to an aspect is to intuitively grasp the meaning of its 'kernel'(Basden, 1997). Details are presented at Table 1. In Dooyeweerd's theory of modal aspects, aspects are perceived as spheres of meaning. These aspects explain the different angles of examining an object and its functions based on reality.

Table 1

Dooyeweerd's aspects cover a wide range of characteristics, which are discussed in Basden (2018). We explain the characteristics which serves the aim of this paper:

1. Dooyeweerd's aspects are irreducibly distinct among themselves.

11

This is the peer reviewed version of the following article: JONEIDY, S. AND BURKE, M. (2018), TOWARDS A DEEPER UNDERSTANDING OF MEANINGFUL USE IN ELECTRONIC HEALTH RECORDS. HEALTH INFO LIBR J., which has been published in final form at https://doi.org/10.1111/hir.12233. This article may be used for non-commercial purposes in accordance with Wiley Terms and Conditions for Use of Self-Archived Versions. 
They are distinct in their kernel meanings, and their laws. To Dooyeweerd aspects are spheres of meaning and law that constitute a law side. Nothing can exist or occur in the cosmos without them, and they account for the diversity and coherence of that being and occurrence. For example lingual aspect's kernel meaning encompasses symbol, signification, expression, words, text and these are distinct from social aspect's kernel meaning which encompasses respect, status, class, grouping, friendship, community.

By irreducible Dooyeweerd means aspects kernel meanings cannot be expressed in terms of one another. The lingual aspect cannot be explained in term of the social aspect. There is no antinomy between them because the laws of one aspect is distinct and irreducible to another. Any attempt to reduce one aspect to another would cause disharmony. They do not emerge from each other and in order to have a full picture we need all aspects.

2. Dooyeweerd's aspects are all equally important.

Equal importance of all aspects serves the characteristic of balance between aspects. When Dooyeweerd speaks of balance between aspects, he is not talking of a kind of 'balance of powers' to resolve a conflict, as it was talked about between Greece and Rome, or between Christianity and modern humanism. It is simply because aspects are not in conflict with each other as they are an unbreakable coherence. Because of this coherence all aspects are dependent upon one another and influence one another, it is necessary to function well in every aspect in order to achieve optimum well-being, success or prosperity. Functioning poorly in any aspect jeopardises the sustainability and success of the whole person, community, enterprise, field of research, etc.

What Dooyeweerd scholars have recently named the 'Shalom Hypothesis' takes this further by stating that all the aspects work in harmony and we must function well in every aspect if we wish to achieve goodness.

\section{2}

This is the peer reviewed version of the following article: JONEIDY, S. AND BURKE, M. (2018), TOWARDS A DEEPER UNDERSTANDING OF MEANINGFUL USE IN ELECTRONIC HEALTH RECORDS. HEALTH INFO LIBR J., which has been published in final form at https://doi.org/10.1111/hir.12233. This article may be used for non-commercial purposes in accordance with Wiley Terms and Conditions for Use of Self-Archived Versions. 
This Hebrew word is used since there is no adequate English equivalent to express what is meant: a deep and lasting peace, health, prosperity and well-being, with strong overtones of completeness and wholeness. If we function poorly in any aspect, it jeopardises the 'whole' functioning. A good example is a person who is committed to his family, he is loving, he is fun, sociable, wealthy, creative, articulative, logical, but because he is eating a lot of junk food he is not healthy and have disease and he is not functioning well in the biotic aspect.

3. Dooyeweerd's aspects are inter-dependant

Dooyeweerd explains the inherent coherence of the aspects in terms of: 1) order, 2) dependency and 3) analogy.

1) Order: Dooyeweerd held that aspects are sequential. One comes after another. This should not cause us seeing them from lower to higher, because as we mentioned that Dooyeweerd believed all aspects are equally important. So the sequence of aspects should be seen as earlier to later instead. In this order aspects retrocipate earlier (foundational) aspects and anticipate later aspects.

2) Dependency: Dooyeweerd's aspects 'need' each other in the anticipatory and differently in the retrocipatory directions. In the retrocipatory way, the functioning in an aspect depends on good functioning in earlier ones; for example formative functioning depends on good analytic functioning. In the anticipatory way an aspect's meaning is fulfilled by reference to meaning of later aspects; for example the functioning in the analytic aspect is infertile if it does not enable functioning in the formative aspect.

3) Analogy: This refers to where each aspect's meaning is echoed in the others aspects For instance when we say a joyful 'gathering', it is social analogy in the aesthetic aspect.

13

This is the peer reviewed version of the following article: JONEIDY, S. AND BURKE, M. (2018), TOWARDS A DEEPER UNDERSTANDING OF MEANINGFUL USE IN ELECTRONIC HEALTH RECORDS. HEALTH INFO LIBR J., which has been published in final form at https://doi.org/10.1111/hir.12233. This article may be used for non-commercial purposes in accordance with Wiley Terms and Conditions for Use of Self-Archived Versions. 
Each aspect reflects within itself but also reaches beyond to all other aspects. In conclusion, these aspects are irreducible and coherent. It is therefore, possible to address diversity by characterizing contemporary life using this set of aspects (Choi, 2006).

Table 1 shows the aspects in its order with each of the aspects kernel meanings. Each sphere of meaning encompasses a whole constellation of concepts that are constraints, objects, goals, events, norms, processes, motivations, perspectives, relationships, freedoms, properties and the like (Choi,2006;Basden\&WoodHarper,2006;Basden,1997).

As aspects govern everyday reality and theoretical analysis is part of the everyday reality many authors have applied Dooyeweerd's notion of irreducible aspects as tools for theoretical analysis (Basden \&WoodHarper,2006; Basden\&Burke,2004;De Raadt,1995;Winfield,2000;Eriksson,2001;Kane,2006;).

\section{Research Methodology}

We choose a set of seminal research papers published in the Health IT journal literature. This section explains how the seminal papers were selected and discusses what factors were meaningful to the authors who initiated the discourses.

\section{Selecting the seminal papers}

The following steps were taken into consideration when selecting the papers:

The first step was to consider if the specific paper has been cited sufficiently and often enough to be regarded as a guiding influence. Since the Meaningful Use of EHRs is a recent field of research, we choose

14

This is the peer reviewed version of the following article: JONEIDY, S. AND BURKE, M. (2018), TOWARDS A DEEPER UNDERSTANDING OF MEANINGFUL USE IN ELECTRONIC HEALTH RECORDS. HEALTH INFO LIBR J., which has been published in final form at https://doi.org/10.1111/hir.12233. This article may be used for non-commercial purposes in accordance with Wiley Terms and Conditions for Use of Self-Archived Versions. 
papers with over 30 citations. To be cited sufficiently, though important, is also a matter of time and could not be the only criterion for selecting seminal papers. This led us to the next criterion.

The second step was to consider if the paper made a substantial scholarly contribution. If the answer to this question was yes, then the third step was to ask, how explicitly the motivation for research (what is important) was expressed in each specific paper.

By following these steps, we were able to choose papers that are moving the field forward by introducing new research problems. Six papers revealed themselves as seminal papers by taking the three steps iteratively and it was concluded after careful thought that these were most likely to show what is meaningful in the minds of their proponents.

- The DesRoches et al. (2012) paper was chosen as seminal because the authors affirm the benefits of EHRs and question the slow rate adoption in small, rural hospitals (DesRoches et al., 2012)

- Hogan and Kissam's (2010) paper was chosen as seminal because they affirm the use of EHRs functionalities by physicians and question the availability of specific functions (Hogan\&Kissam,2010)

- The Krist and Woolf's (2011) paper was chosen as seminal because they affirm the use of EHRs by clinicians and question the EHRs which are not patient-driven (Krist\&Woolf,2011).

- The Bowens,Frye\&Jones' (2010) paper was chosen as seminal because they affirm the resistance to use EHRs and question the integration of EHRs into the workflow of a the hospital. (Bowens,Frye\&Jones,2010).

- Bates and Bitton's (2010) paper was chosen as seminal because they affirm the provision of more EHRs functionalities and question lack of support for primary care (Bates\&Bitton,2010).

15

This is the peer reviewed version of the following article: JONEIDY, S. AND BURKE, M. (2018), TOWARDS A DEEPER UNDERSTANDING OF MEANINGFUL USE IN ELECTRONIC HEALTH RECORDS. HEALTH INFO LIBR J., which has been published in final form at https://doi.org/10.1111/hir.12233. This article may be used for non-commercial purposes in accordance with Wiley Terms and Conditions for Use of Self-Archived Versions. 
- The Lanham,Leykum\&McDaniel's (2011) paper was chosen as seminal because they affirm the importance of integration between EHRs and workflows, and question the communication patterns and harmonies at hospital level (Lanham, Leykum \&McDaniel,2011).

The other papers may be made use of in later research but to a lesser extent, as, although they clearly indicate what is meaningful to the discourse, they were not selected, as they merely repeat what was said in the seminal papers.

\section{Selecting the text}

Three steps were followed in selecting each paper. 1. A review of the abstract, introduction and conclusion of the paper, to select relevant passages. The selection is based on passages with normative tone, expressions of motivation, and/or explicitly indicating what is important to the authors. 2. A thorough and careful read through the whole paper, to check whether the papers introduce any other meaningful issues in the body of the paper that were not found in the abstract, introduction and conclusion. 3 . Undertake the aspectual analysis of the selected texts to disclose the reasons regarding "the authors' choice of meaningful topics and how - what was important to the authors' paper - is meaningful. 4. Iterate as necessary.

\section{Detecting what is meaningful}

In Step 1 above, several methods were used to reveal what is meaningful to authors. One was to look for explicit statements of motivation, such as "I am motivated to..." or "I am inspired by...". Motivation is what is important to the authors which made them want to add to the literature in this area in new ways. However, often the motivation is not explicitly stated, and might be implicit in the wording used by the author. Where this is the case, what is important must be carefully revealed. Two factors can reveal this, as follows. The

\section{6}

This is the peer reviewed version of the following article: JONEIDY, S. AND BURKE, M. (2018), TOWARDS A DEEPER UNDERSTANDING OF MEANINGFUL USE IN ELECTRONIC HEALTH RECORDS. HEALTH INFO LIBR J., which has been published in final form at https://doi.org/10.1111/hir.12233. This article may be used for non-commercial purposes in accordance with Wiley Terms and Conditions for Use of Self-Archived Versions. 
first is to search for normative sentences, such as “..., hospitals must have functioning electronic health record systems that contain patient demographics...". Those are not found in all seminal papers.

A second way to notice linguistic devices like "Nevertheless" or "However". Such words, though grammatically correct are merely conjunctions, that often contain a force which indicates the author is trying to state something important. Contrasts or linking to something that the field believes "good" can also indicate the author's desire to emphasize something important.

Since Dooyeweerd aspects are spheres of meaning, they are useful to detect the meaning of what the author's desire to emphasize in their papers. Dooyeweerd emphasized the kernel meanings of aspects are understood intuitively rather than by theoretical thought, because we are immersed in them as they enable us to function. So they were relatively straightforward for an experienced analyst to employ in both practical analysis and in the empirical stages of academic research. So each person's understanding of what is meaningful in each aspect will differ, according to their experience. Since aspects are spheres of meaning, both researcher and researched are likely to have a shared background understanding of them even if a researcher cannot clearly identify an aspect. Using aspects should be able to reveal the taken-for-granted perspective of both the researcher (analyst) and the researched; this was found to be so by both Winfield (2000) and Kane (2006).

\section{Results}

In this section we aspectually analyze six papers.

\section{DesRoches et al (2012) on Adoption of EHRs}

One of the leading papers on Meaningful Use of EHRs is by DesRoches et al. In the abstract they state:

This is the peer reviewed version of the following article: JONEIDY, S. AND BURKE, M. (2018), TOWARDS A DEEPER UNDERSTANDING OF MEANINGFUL USE IN ELECTRONIC HEALTH RECORDS. HEALTH INFO LIBR J., which has been published in final form at https://doi.org/10.1111/hir.12233. This article may be used for non-commercial purposes in accordance with Wiley Terms and Conditions for Use of Self-Archived Versions. 
"The proportion able to meet our proxy criteria for meaningful use also rose; in 2011,

18.4 percent of hospitals had these functions in place in at least one unit and 11.2 percent had them across all clinical units. However, gaps in rates of adoption of at least a basic record system have increased substantially over the past four years based on hospital size, teaching status, and location."

In the passage above "However" is used as a device to catch the readers' attention regarding the gaps in rates of adoption of EHRs. Gap on its own is of the spatial aspect as it refers to a space or an interval between two objects. But here, "gaps in rates of adoption of at least a basic record system have increased substantially over the past four years...." is a functioning in the analytic aspect. It is in the analytic aspect because this shortcoming in adoption of EHRs has been raised in the author's awareness and it is therefore shown to be of importance to them.

"Since 2008, when we first started systematically monitoring adoption, the percentage of hospitals with any EHR system grew by approximately three percentage points each year, reaching 15 percent in 2010.However, these early surveys were conducted before implementation of the meaningful-use incentives."

Similar to the previous passage, "However" is used a device to emphasize the importance of a gap. "These early surveys were conducted before implementation of the meaningful-use incentives." The missing part of the previous survey is the incentive to using technology in a meaningful way - i.e. meaningful use incentives. Again the authors of the paper are raising the importance of a concept which is missed in previous surveys. Awareness of the concept is an analytic function.

18

This is the peer reviewed version of the following article: JONEIDY, S. AND BURKE, $M$ (2018), TOWARDS A DEEPER UNDERSTANDING OF MEANINGFUL USE IN ELECTRONIC HEALTH RECORDS. HEALTH INFO LIBR J., which has been published in final form at https://doi.org/10.1111/hir.12233. This article may be used for non-commercial purposes in accordance with Wiley Terms and Conditions for Use of Self-Archived Versions. 
"Small, nonteaching, and rural hospitals continue to adopt electronic health record systems more slowly than other types of hospitals."

DesRoches et al. also considers the slowness in the rates of adoption. Slowness on its own may cause thinking of speed! Speed is not in the kinematic aspect but it could be kinematic amount! The quantitative characteristic of movement. However, slowness in rates of adoption is a measuring activity which is placed in the quantitative aspect.

"To date, the pace of adoption of EHR systems in US hospitals has been slow, and the future pace of adoption and distribution of adoption across all hospitals remains uncertain."

The pace of adoption is seen as a focal point in the DesRoches et al paper. In the above excerpt, the pace of adoption is also referring to the quantitative characteristic of movement which is in the quantitative aspect.

\section{Hogan and Kissam (2010) on Use of EHRs' functionalities}

One of the six papers that provided a review on defining Meaningful Use in the Health Affairs was Hogan and Kissam's study. The passage below shows what motivates them in their research.

“..... among physicians who have electronic health records, between 75-85 percent are already using functions that meet some of the proposed criteria for demonstrating meaningful use. But gaps remain”

They used the word "But" as device to tell the reader what motivated them for their paper: "gaps remain". Recognizing gaps in the previous studies is human functioning in the analytic aspect. It is the analytic aspect

19

This is the peer reviewed version of the following article: JONEIDY, S. AND BURKE, M. (2018), TOWARDS A DEEPER UNDERSTANDING OF MEANINGFUL USE IN ELECTRONIC HEALTH RECORDS. HEALTH INFO LIBR J., which has been published in final form at https://doi.org/10.1111/hir.12233. This article may be used for non-commercial purposes in accordance with Wiley Terms and Conditions for Use of Self-Archived Versions. 
as the remaining gap is distinguished from what has been achieved so far by Meaningful Use program. They expanded what they meant by gaps in the background of their study. The following paragraph is an example of this.

"Previous work to quantify and report the use of specific electronic health record functions has been limited. The National Centre for Health Statistics, part of the Centres for Disease Control and Prevention $(C D C)$, uses a mail supplement to the National Ambulatory Medical Care Survey to measure the adoption of any partially or fully electronic health record by office based physicians. The survey also asks about specific electronic health record functions to determine whether these are available to physicians. However, data from the survey are not analysed to examine how many providers report having specific functions available but have them "turned off or not used."

In the above passage "However" is used as a device in to reveal an expanded version of their motivation. “...data from the survey are not analysed to examine how many providers report having specific functions available...". This is in the juridical aspect because justice was not applied to the available data. For Hogan and Kissam a deeper analysis of the use of EHRs was important. They identify a lack of reporting on a particular important issue- the availability of functions. By analysing the data from the survey this would give justice to studying Meaningful Use of EHRs and this would then fulfil the juridical aspect.

The actual act of recognition of gaps in the previous study is itself in the analytic aspect. Most studies are aimed to be motivated by a gap in the previous literature. But what is that gap? The nature of the gap can be the analytic aspect too or it could be within other aspects.

20

This is the peer reviewed version of the following article: JONEIDY, S. AND BURKE, $M$ (2018), TOWARDS A DEEPER UNDERSTANDING OF MEANINGFUL USE IN ELECTRONIC HEALTH RECORDS. HEALTH INFO LIBR J., which has been published in final form at https://doi.org/10.1111/hir.12233. This article may be used for non-commercial purposes in accordance with Wiley Terms and Conditions for Use of Self-Archived Versions. 


\section{Krist and Woolf (2011) on the Patients' engagement with EHRs}

In their paper, Krist and Woolf aim to provide a vision for patient-centered Health Information Systems. The following paragraph indicates their motivation for their paper:

"The health information technology movement focuses much of its energy on the use of electronic medical records by clinicians, but the use of information technology by patients carries equal promise.

In the passage above, Krist and Woolf used "but" as a conjunction, a device to emphasize the importance of patient experience as part of Meaningful Use. "But the use of information technology by patients carries equal promise" is mainly functioning in the social aspect because the emphasize is on patients as a social group who deserve using EHRs in its best form and design. Krist and Woolf believed current EHRs provide too much unmodified content to the patient.

The following passage helps in affirming the social aspect.

"Information technology holds great promise in empowering patients to manage their health, but the patient must become the focus of the design if the technology is to be used or fulfill its potential."

"but the patient must become the focus...." is about designing EHRs which is relevant to this highly important social group. This is placed in the social aspect.

The second important aspect driving their motivation in their paper is the formative aspect. For example:

21

This is the peer reviewed version of the following article: JONEIDY, S. AND BURKE, M. (2018), TOWARDS A DEEPER UNDERSTANDING OF MEANINGFUL USE IN ELECTRONIC HEALTH RECORDS. HEALTH INFO LIBR J., which has been published in final form at https://doi.org/10.1111/hir.12233. This article may be used for non-commercial purposes in accordance with Wiley Terms and Conditions for Use of Self-Archived Versions. 
"Outside of health care, the public routinely uses computers and smart phones to access information and perform tasks with a click of a button. Patients seek similar ease in accessing health information, but health care has been slow to develop information tools for patients of comparable functionality."

Krist and Woolf express their motivation also by "but health care has been slow to develop information tools for patients of comparable functionality." Developing, formation and design of EHRs which suits patient is in the formative aspect. The following passage may help in understanding the importance of the formative aspect.

"Higher functionality exists in some high-end systems, but even these cannot deliver the full spectrum of services, and their developers report slow adoption"

As the above excerpt shows, to give justice to patients requires design and technology that could deliver the full spectrum of service. The slow development and design are formative functioning.

\section{Bowens, Frye \& Jones (2010) on Resistance to EHRs Adoption}

Resistance to adoption of EHRs is another area of research which requires the attention of those involved in the creation of policy for Meaningful Use of EHRs. Bowens et al consider resistance to adoption of EHRs as significant as EHRs benefits. They explain their motivation as:

"The researchers conclude that widespread adoption and meaningful use of EHR technology rely on the successful integration of health information technology (HIT) into clinical workflow. Without successful integration of HIT into clinical workflow, clinicians in today's

\section{2}

This is the peer reviewed version of the following article: JONEIDY, S. AND BURKE, $M$. (2018), TOWARDS A DEEPER UNDERSTANDING OF MEANINGFUL USE IN ELECTRONIC HEALTH RECORDS. HEALTH INFO LIBR J., which has been published in final form at https://doi.org/10.1111/hir.12233. This article may be used for non-commercial purposes in accordance with Wiley Terms and Conditions for Use of Self-Archived Versions. 
ambulatory care settings will continue to resist adoption and implementation of EHR technology."

In the passage above Bowens et al use the "without" to show a key element is missing. That is "integration of HIT into clinical workflow". If successful integration refer to careful balance between HIT and clinical workflow, then it is a functioning in the aesthetic aspect. Integration on its own is also a functioning in the aesthetic aspect. By considering the following two excerpts we can affirm that the aesthetic aspect is one of the core aspects shaping the Bowens et al motivation for their research.

\footnotetext{
"Clinicians must now contemplate how "meaningful use" plays a role in the overall integration
} of EHR technology into ambulatory care settings."

"As the leader of change, the EHR champion must engage staff and seek continuous feedback from staff throughout the implementation process."

"Overall integration" and "the EHR champion must engage staff and seek continuous feedback from staff throughout the implementation process" is about bringing harmony to all parts such as a symphony that is the aesthetic aspect.

In the following paragraph Bowens et al reveal the next important aspect, the pistic!

"Studies show that implementation of Health IT may improve health outcomes, reduce medication errors, augment chronic disease management, reduce health disparities, and offer substantial cost savings. Despite these benefits, clinicians continue to be reluctant to integrate health information technologies such as electronic health records (EHRs) into ambulatory care settings......"

23

This is the peer reviewed version of the following article: JONEIDY, S. AND BURKE, M. (2018), TOWARDS A DEEPER UNDERSTANDING OF MEANINGFUL USE IN ELECTRONIC HEALTH RECORDS. HEALTH INFO LIBR J., which has been published in final form at https://doi.org/10.1111/hir.12233. This article may be used for non-commercial purposes in accordance with Wiley Terms and Conditions for Use of Self-Archived Versions. 
Bowens et la used "Despite" to express the contrast between two important things: benefits versus lack of faith. Reluctant to integrate may come from a lack of belief and commitment to EHRs. Clinicians are in doubt about EHRs. The reluctance of this sort is a function of the pistic aspect. Both the pistic and the aesthetic aspect are important to Bowens et al.

\section{Bates and Bitton (2010) on Use of EHRs in the Medical Home Services}

Meaningful Use of EHRs has to reach all the geographical areas of the US health system. Bates and Bitton believe this has not yet happened. The following excerpt may explains why.

"Providing excellent primary care is central to the delivery of high-quality medical care and, more broadly, to the health of populations. However, the United States does not have enough primary care today. Also, the primary care that exists is too often delivered by providers working in small practices without adequate support. These providers face difficulties in coordinating their activities with those of the rest of the health care system."

The authors use "However" as a device to send an important message which is ," the United States does not have enough primary care today. " Lack of enough primary care is about lack of due and justice to the people of the ground. Obligation of this kind is a function in the juridical aspect. The following two excerpts from this paper affirm the importance of the juridical aspect

"The electronic health record is widely believed to be central to the medical home concept. ${ }^{4}$ Yet even today's leading electronic health records do not include much of the functionality that will be required to transform the care of chronically ill patients."

24

This is the peer reviewed version of the following article: JONEIDY, S. AND BURKE, M. (2018), TOWARDS A DEEPER UNDERSTANDING OF MEANINGFUL USE IN ELECTRONIC HEALTH RECORDS. HEALTH INFO LIBR J., which has been published in final form at https://doi.org/10.1111/hir.12233. This article may be used for non-commercial purposes in accordance with Wiley Terms and Conditions for Use of Self-Archived Versions. 
"we believe that today's electronic health records perform most poorly in the domains of team care and care transitions, for which almost no functionality is in place."

EHRs needs to include more functionality to improve health services in the other domains. This is a requirement that has to be addressed and it is clearly a juridical functioning.

"...the primary care that exists is too often delivered by providers working in small practices without adequate support."

The authors are pointing to the lack of support for providers which highlight functioning in the ethical aspect to the detriment of the healthcare system. Support is a function in the ethical aspect and is mentioned in the following excerpt.

"But recent evidence suggests that current electronic health records do not adequately support even today's care coordination needs",

The juridical aspect highly anticipates the ethical aspect. Bates and Bitton are very motivated by these two aspects.

\section{Lanham,Leykum\&McDaniel (2011) on Role of Communication in Use of EHRs}

Lanham et al. believes little is known on how communication patterns are associated with use of EHRs at the practice level. The following excerpts show their motivation arises from differences in communication patterns in different practices.

25

This is the peer reviewed version of the following article: JONEIDY, S. AND BURKE, $M$. (2018), TOWARDS A DEEPER UNDERSTANDING OF MEANINGFUL USE IN ELECTRONIC HEALTH RECORDS. HEALTH INFO LIBR J., which has been published in final form at https://doi.org/10.1111/hir.12233. This article may be used for non-commercial purposes in accordance with Wiley Terms and Conditions for Use of Self-Archived Versions. 
“Despite efforts made by ambulatory care organizations to standardize the use of electronic health records (EHRs), practices often incorporate these systems into their work differently from each other."

They show the importance of the aesthetic aspect by saying "practices often incorporate these systems into their work differently from each other". The keyword here is 'differently'. To reason why it is a keyword and why the authors show the importance of the aesthetic aspect we need to read more excerpts from this paper.

"One potential factor contributing to these differences is within-practice communication patterns. The authors explore the linkage between within-practice communication patterns and practice-level EHR use patterns."

In the above passage, the authors unfold the causes of the differences by mentioning "withinpractice communication patterns". It is clear that this is lingual functioning because there is a variation in how medical professionals express and understand the use of EHRs. So the lingual aspect is very evident. To find out why the aesthetic aspect is important, Lanham et al explain more in the following excerpts.

"We define standardized EHR use as EHR use that is uniformly high across all users within a practice."

"For example, in practices where communication patterns are cohesive, perhaps working with one physician or nurse on EHR issues may be sufficient to improve EHR use throughout the practice. In practices where communication patterns are more fragmented, EHR support staff 26

This is the peer reviewed version of the following article: JONEIDY, S. AND BURKE, M. (2018), TOWARDS A DEEPER UNDERSTANDING OF MEANINGFUL USE IN ELECTRONIC HEALTH RECORDS. HEALTH INFO LIBR J., which has been published in final form at https://doi.org/10.1111/hir.12233. This article may be used for non-commercial purposes in accordance with Wiley Terms and Conditions for Use of Self-Archived Versions. 
may need to work with each individual to achieve EHR use goals set by the larger organization."

The above passage reveals the importance of cohesive patterns of communication. This facilitated use of EHRs is uniformly high across all users within practices and it is clear that the emphasis in the paper on coherence and harmony is aesthetic functioning.

Now that we have aspectually analyzed what is meaningful to the authors of the six papers we display the main aspects of what is primarily and secondary meaningful in Table 2 below. The rows display the aspects and the columns indicate the authors of the papers.

This table highlights a number of significant factors which we discuss in the next section.

Table 2

\section{Variety of Meaningful Aspects}

Table 2 shows a number of different aspects as meaningful in different papers. There are aspects that are covered by only one seminal paper. That means that only that seminal paper sees that aspect as meaningful as its main concern. In each seminal paper in the field of Meaningful Use of EHRs, the use of EHRs is conceived in a different way. Some individual researchers might work within several ways of understanding of use of EHRs. Table 2 shows the overlaps between papers too. These are overlaps between primary aspects such as the Analytical Aspect, and secondary aspects such as the Aesthetic Aspect.

Primary aspect is the aspect that gives an entity its major meaning. In Dooyeweerd's term, it is called - the qualifying aspect. By secondary aspect, we mean the founding aspect. Founding aspect is a Dooyeweerdian term and (Basden, 2002) explains it as the aspect that guided a thing's coming-into-being, it is the aspect 27

This is the peer reviewed version of the following article: JONEIDY, S. AND BURKE, M. (2018), TOWARDS A DEEPER UNDERSTANDING OF MEANINGFUL USE IN ELECTRONIC HEALTH RECORDS. HEALTH INFO LIBR J., which has been published in final form at https://doi.org/10.1111/hir.12233. This article may be used for non-commercial purposes in accordance with Wiley Terms and Conditions for Use of Self-Archived Versions. 
that most explains the thing's unique actuality. For example, a tree is qualified by the biotic aspect. But what makes one tree different from another? It can be physical conditions. So the tree, though qualified by the biotic aspect might be founded in the physical aspect

So far we have used Dooyeweerd's aspects as a tool to analyze the seminal papers. Next, we discuss the value of the Dooyeweerdian approach for analyzing the seminal papers in the field of Meaningful Use of EHRs

\section{Discussion: Making sense of the diversity of seminal papers}

To understand the diversity of seminal papers found in the literature, we use the results of empirical work demonstrated in the Table 2 and present them into Table 3. Table 2 represent the result of analysis by papers and Table 3 represent the results by the aspects.

In Table 3 column 1 displays the list of aspects. Column 2 express the kernel meaning of each aspect. Column 3 identifies in which of the seminal papers each aspect might be important. Out of Dooyeweerd's fifteen aspects Table 3 presents nine aspects. It offers a useful range of what is important to the authors of seminal papers in the field of Meaningful Use of EHRs. Each seminal paper, from a Dooyeweerdian point of view is multi-aspectual, however our aspectual analysis revealed in that most of the seminal papers only two aspects predominate.

Table 3

From the diversity of papers three questions might be raised: 1) Are these seminal papers really different? 2) are there any issue missing that could be indicated by new papers? 3) Is there any relationship between

28

This is the peer reviewed version of the following article: JONEIDY, S. AND BURKE, M. (2018), TOWARDS A DEEPER UNDERSTANDING OF MEANINGFUL USE IN ELECTRONIC HEALTH RECORDS. HEALTH INFO LIBR J., which has been published in final form at https://doi.org/10.1111/hir.12233. This article may be used for non-commercial purposes in accordance with Wiley Terms and Conditions for Use of Self-Archived Versions. 
the papers? In order to discuss these questions, in the following paragraphs we use three characteristics of aspects: 1) Irreducibility 2) Balance and Shalom 3) Inter-aspect dependency.

1. Are these seminal papers really different?

Dooyeweerd's aspects are distinct and irreducible to each other. As Table 2 shows Irreducible diversity of meaning is evident. Note that each seminal paper finds a pair of different aspects important and some aspects are important in only one paper.

This is the case for both in one seminal paper and between them. Krist and Woolf (2011) finds patients as equally important as developing the EHRs. One is centered on the social aspect and the other one on the formative aspect. Both are important and cannot be reduced to each other. Looking at two seminal papers, Lanham, Leykum \& McDaniel (2012) is motivated by within-practice communication pattern (the lingual aspect) and cohesive pattern of communication (the aesthetic aspect), whereas Krist and Woolf (2011) emphasize is on social and the formative aspect. None of these aspects are reduced to each other, so the papers are really distinct and different. Yet we still have some overlaps between papers.

Hogan and Kissam (2010) and Bates and Bitton (2010) papers have overlaps on the juridical aspect. For instance, Lack of primary care and the data which has not been analysed both function in the juridical aspect, but what makes the two papers different from each other is the different viewpoints of the analytical and the ethical aspects. Hogan and Kissam (2010) finds gaps in using functions important while a lack of support for providers is important to Bates and Bitton. . Whilst other aspects overlap, the papers discourse around different topics that cannot be reduced to each other. It is irreducibility of aspects that enable us to address this question.

2. Are there any issue missing that could indicate new seminal papers?

29

This is the peer reviewed version of the following article: JONEIDY, S. AND BURKE, M. (2018), TOWARDS A DEEPER UNDERSTANDING OF MEANINGFUL USE IN ELECTRONIC HEALTH RECORDS. HEALTH INFO LIBR J., which has been published in final form at https://doi.org/10.1111/hir.12233. This article may be used for non-commercial purposes in accordance with Wiley Terms and Conditions for Use of Self-Archived Versions. 
Dooyeweerd aspects are all equally important and functioning well in all aspects can bring goodness in terms of completeness. As Table 3 shows, there are aspects which are not covered by any paper. Clearly certain aspects are not considered as important in the field, namely from spatial to sensitive. This might be explained by the fact that mathematical and pre-human aspects are less likely to be important aspects in the meaningful use context. However, Table 2 demonstrates that in DesRoches et al. (2012) study, the quantitative aspect that arises from the mathematical level is important. This encourages us in thinking why other mathematical and pre-human aspects have not received attentions. Another missing aspect is the economic aspect. What would be the economic aspect of Meaningful Use of EHRs? Despite strong financial and managerial incentives for implementing EHRs, this aspect surprisingly has not been a motivational aspect for the authors. If we really want to understand Meaningful Use of EHRs we need research into issues around those aspects which are not yet covered.

Meaningful Use of EHRs is multi-aspectual and research into all aspects of it would bring balance to the field. And if the motivation for research is centered on functioning well in all aspects, the community of researchers in the field would bring goodness (i.e. shalom) to the field. Table 3 shows that analytic, aesthetic and the juridical aspects have slightly received more attention. This might reflect the fact that researchers of this field are more motivated by the gap in data, integration of EHRS and workflow and giving justice to the patients. By research into the spatial, kinematic, physical, biotic, psychic and economic aspects a more balanced field would be possible. For example the economic aspect of Meaningful Use of EHRs could involve issues which are centred on important resources in every clinic and hospital. Therefore, the field would benefit from attention given to the remaining aspects.

Although a full study of more papers might reveal a different balance between aspects, the notion of shalom and balance between aspects enable us to address this question.

This is the peer reviewed version of the following article: JONEIDY, S. AND BURKE, $M$. (2018), TOWARDS A DEEPER UNDERSTANDING OF MEANINGFUL USE IN ELECTRONIC HEALTH RECORDS. HEALTH INFO LIBR J., which has been published in final form at https://doi.org/10.1111/hir.12233. This article may be used for non-commercial purposes in accordance with Wiley Terms and Conditions for Use of Self-Archived Versions. 
3. Is there any relationship between papers?

Dooyeweerd would seek to address this question by examining inter-aspect dependency. Inter-aspect dependency means each aspect depends on all other aspects for its full meaning. For example, the social aspect is facilitated by the lingual aspect (Foundational Dependency) and the potential of the lingual aspect for facilitating the social aspect depends on the meaning it provides (Anticipatory Dependency). Full patient engagement with EHRs (i.e. the social aspect) cannot be facilitated without functionalities (for example: a well-designed call to action button that facilitates a direct chat with a specialist) on the EHRs interfaces (the lingual aspect). By staying in the realm of the lingual aspect, full patient engagement with EHRs has no meaning except within the social aspect. The meaning of a call to action button is fulfilled when a patient (the social aspect) clicks on it to have a direct chat with a specialist.

The Inter-aspect of dependency explains the relationship between the seminal papers. If within-practice communication (i.e. the lingual aspect) enables a more patient-driven approach (i.e. the social aspect) then Lanham et al. paper can be related to the Krist and Woolf study. The Dooyeweerd analytic aspects enables the formative aspect, therefore it is reasonable. If the gap in using EHRs (i.e. the analytic aspect) encourages the need for developing EHRs which are easier to use (i.e. the formative aspect). then there is a relation between Hogan and Kissam's paper and Krist and Woolf paper. If a cohesive pattern of communication (i.e. the aesthetic aspect) both within and between hospitals can facilitate the expansion of primary care from small practices to larger practices (i.e. the juridical aspect), then the Lanham et al. study is related to Bates and Bitton's. Dooyeweerd ethical aspect enables the pistic aspect and so Bates and Bitton's paper may be seen as related to Bowens et al's, as providing a standard level of support (i.e. the ethical aspect) empowers and gives confidence (i.e. the pistic aspect) to clinicians to integrate EHRs into ambulatory care setting. The inter-aspect dependency of aspects help us in addressing this question.

31

This is the peer reviewed version of the following article: JONEIDY, S. AND BURKE, M. (2018), TOWARDS A DEEPER UNDERSTANDING OF MEANINGFUL USE IN ELECTRONIC HEALTH RECORDS. HEALTH INFO LIBR J., which has been published in final form at https://doi.org/10.1111/hir.12233. This article may be used for non-commercial purposes in accordance with Wiley Terms and Conditions for Use of Self-Archived Versions. 
We have shown the value of Dooyeweerd's philosophy, which is beyond what has been discussed in the field of Meaningful Use of EHRs. The analysis of seminal papers by using Dooyeweerd's philosophy reveals a diversity of aspects on what is most meaningful to the authors regarding the use of EHRs. This helps to make Meaningful Use researchers aware of the importance of the diversity of aspects. This study integrates the seminal papers as representative of six different discourses of Meaningful Use of EHRs without combining them together into one. The distinction of aspects allows each paper its own place in the field. The notion of shalom tells us that the field can bring goodness/ completeness as all aspects are equally important and research into the missing aspects would be very useful.. Inter-aspect dependency helps to integrate the papers together whilst they still have their own distinct place in the field.

\section{Potential Implications:}

In the background section of this paper, we have stated that our research aim was to introduce a way of making sense of the diversity in research in the field of Meaningful Use EHRs. In this section we return to our aim. Dooyeweerd's philosophy suggested a way of analyzing and understanding the diversity. We applied his suite of aspects to analyze seminal papers and revealed its fruitfulness to the Health IT field of research in regard to the Meaningful Use of EHRs. Thus this research has several important implications.

Firstly, by conducting aspectual analysis to understand the significance of seminal papers, which is a step beyond the point of merely collecting and categorizing data. Sakai concluded that vocabulary has the highest critical factor in preparing quality patient information (Sakai, 2013). Clarke et al. in their review of papers, emphasized the most common information needs (Clarke et al., 2013). But we found what is important to each author in the text and aspectual analysis enabled us to understand what is meaningful to them. Dooyeweerd helped us to realize what is significant to the authors of seminal papers can be balanced with what is meaningful, and what is meaningful has the normative force of law of aspects. This

This is the peer reviewed version of the following article: JONEIDY, S. AND BURKE, $M$. (2018), TOWARDS A DEEPER UNDERSTANDING OF MEANINGFUL USE IN ELECTRONIC HEALTH RECORDS. HEALTH INFO LIBR J., which has been published in final form at https://doi.org/10.1111/hir.12233. This article may be used for non-commercial purposes in accordance with Wiley Terms and Conditions for Use of Self-Archived Versions. 
meaningfulness should be regarded for the community, not just the individual author. So that it is not just what authors happen to find meaningful, but what they find meaningful can be linked to -and helpful to the whole community. This approach creates a new way for any future papers in the field of Meaningful Use of EHRs to be clearly analysed.

Secondly, by acknowledging the application of Dooyeweerd's aspects. 1) Irreducibility of aspects helped to distinguish seminal papers from each other and identify possible overlaps between them. 2) Balance and Shalom of aspects helped to identify what aspects are missing. The missing aspects need attention in the field of study and new discourses can be centered on them. 3) Inter-aspect dependency helped to investigate the relationship between seminal papers. Usually fields are fragmented and now in the method suggested in this study, we are able to bring them together. With the application of Dooyeweerd's aspects we propose a new approach in integrating the "Meaningful Use seminal papers" into a wider spectrum. This approach is one of a pre-theoretical attitude, where it respects the notions that aspects are distinct and coherent therefore allowing the discourses to keep their own individual and distinct place in the field. Dooyeweerd's aspects can also be applied in other fields of studies.

Thirdly, by addressing the motivation behind each research, we demonstrated how Dooyeweerd' aspects can help to reveal the authors' motivations. As stated, authors either express their motivation in an obvious way by using of linguistic 'devices' used in the text, such as "However, gaps in rates of adoption of at least a basic record system have increased substantially over the past four years based on hospital size, teaching status, and location.." in DesRoches et al paper on Adoption of EHRs. Or they use motivational words such as "One potential factor contributing to these differences is within-practice communication patterns." In Lanham et al paper on Role of Communication in Use of EHRs. Dooyeweerd's aspect helped us to find and understand authors' motivations within the texts - which is different from Serenko,Bontis\&Hull's (2011) identification of motivations (Serenko,Bontis\&Hull,2011). The Dooyeweerdian approach in

This is the peer reviewed version of the following article: JONEIDY, S. AND BURKE, M. (2018), TOWARDS A DEEPER UNDERSTANDING OF MEANINGFUL USE IN ELECTRONIC HEALTH RECORDS. HEALTH INFO LIBR J., which has been published in final form at https://doi.org/10.1111/hir.12233. This article may be used for non-commercial purposes in accordance with Wiley Terms and Conditions for Use of Self-Archived Versions. 
revealing motivation can be applied to other academic papers including non-academic texts such as notes, screenplays, official letters, etc.

Fourthly, the research makes a contribution in terms of the identification of diversity from the basis of meaningfulness. Benbasat and Weber addressed diversity in research methodologies, reference disciplines but diversity of research problems remained vague. Vessey,Ramesh\&Glass (2002) identified diversity in IS research problems by looking at topics and by perusing text or key words. In the field of Health IT, Chiasson and Davidson have addressed the diversity in Health IT research by looking at the application of one into another, IT and Healthcare (Chiasson\&Davidson, 2004). We addressed diversity through identifying what was meaningful to the authors of the seminal papers from different discourses centered on Meaningful Use of EHRs. Meaningfulness in Dooyeweerd's sense enabled us to identify and distinguish seminal papers through referring to what is expressed as important and meaningful rather than their research methodologies and reference disciplines. The 15 aspects that Dooyeweerd created helped to systematize the diversity of discourses shaped around the seminal papers. This approach can be replicated and expanded to systematize diversity in research in other fields of study.

\section{Implications of the findings for the LIS sector}

The findings from this paper would also be helpful to those working in a clinical information support role, embedded information specialists and those working within health information management systems. Our findings and ideas would help to increase understanding of the uses of EHR, and the ways in which Meaningful Use can be categorized and ultimately could assist with EHR access, storage and retrieval systems. A study published in 2014 (Corbett, Deardorff\&Kovar-Gough, 2014) reported that health information professionals were very much poised to use data management skills to assist with appropriate

34

This is the peer reviewed version of the following article: JONEIDY, S. AND BURKE, M. (2018), TOWARDS A DEEPER UNDERSTANDING OF MEANINGFUL USE IN ELECTRONIC HEALTH RECORDS. HEALTH INFO LIBR J., which has been published in final form at https://doi.org/10.1111/hir.12233. This article may be used for non-commercial purposes in accordance with Wiley Terms and Conditions for Use of Self-Archived Versions. 
uses of her. In 2017 the US Medical Library Assocation (2017) conducted a review of the types of competencies needed for current and future health information professions - which would be applicable to EHR systems (Medical Library Association,2009). These core competences included expertise in Information Services; Information Management; Instruction; Leadership and Management; Evidence Based practice and Research and Health Information Professionalism (i.e. improving health care and access to health care information). Whilst our study could contribute to most of these competencies it is perhaps in this final competence of Professionalism i.e. - improving access to health care- that would be the most significant for embedded information specialists in future years.

The potential value of the methodology for exploring other similar interpretive problems has been documented in other publications regarding the application of Dooyeweerd's philosophical ideas. These include studies on how interprevist, socio-critical and positivist approaches in systems may be integrated (Basden, 2011); a detailed outline of how Dooyeweerd's philosophical can be applied to systems research is also covered in a later work by the same author (Basden, 2017).

The methodology used in the study reported here could, with some adjustment for context, be repeatable for other similar interpretive problems especially in the health sector. In addition Dooyeweerd's ideas may help with other 21st century problems such as the management of Big Data and new developments in the field of AI.

In this study we have applied Dooyeweerd's philosophy to six seminal papers in the Meaningful Use of EHRs' field. Suggestions for future research could include studies exploring EHRs security regarding privacy of patients and related discourses. As healthcare becomes ever more dependent upon the successful interaction of humans with technology, this study, and the methodology explored within, offers a potential route towards a better understanding of this critical feature of health services delivery

This is the peer reviewed version of the following article: JONEIDY, S. AND BURKE, M. (2018), TOWARDS A DEEPER UNDERSTANDING OF MEANINGFUL USE IN ELECTRONIC HEALTH RECORDS. HEALTH INFO LIBR J., which has been published in final form at https://doi.org/10.1111/hir.12233. This article may be used for non-commercial purposes in accordance with Wiley Terms and Conditions for Use of Self-Archived Versions. 


\section{Conclusion}

This research intended to add to the existing body of knowledge in understanding the field of Meaningful Use of EHRs. The literature that currently exists on Meaningful Use of EHRs stress the rate of adoption of EHRs, whilst the rest tend to focus on the limitations of the adoption studies. Further studies were developed over time and these centered on different discourses. Now the field is proliferated with many discourses which has led to the complexity of the field. This paper aimed to address the diversity of seminal papers in the field of Meaningful Use of EHRs.

The study proposed the use of aspects to analyze seminal papers in addressing the question on how to make sense of the diversity of Meaningful Use of EHRs' field. The contribution of the research is that by employing the lens of Dooyeweerd's aspects - a new insight is beginning to emerge which is useful and robust thereby further enhancing the understanding of diversity in this field. Research that looks at diversity from the lens of meaningfulness gives an opportunity to present itself with equal dignity in all fields. In line with Dooyeweerd's vision to make every day experiences a foundation for theoretical thought and in this way carving new paths for research in various fields that may be addressed and examined in future studies. In this paper, we applied Dooyeweerd's approach to the field of Meaningful Use of EHRs in the U.S. health sector.

This research, however, has some limitations. We have not included each and every published paper centered on, or related to, Meaningful Use of EHRs. The selected papers only provided a context to serve the aim of the research. Taking all the discourses would have given an even wider picture of the field. Some of the omitted discourses, although addressing important issues, might be sub-discourses around specific issues within the discourses identified in this paper.

\section{References:}

This is the peer reviewed version of the following article: JONEIDY, S. AND BURKE, M. (2018), TOWARDS A DEEPER UNDERSTANDING OF MEANINGFUL USE IN ELECTRONIC HEALTH RECORDS. HEALTH INFO LIBR J., which has been published in final form at https://doi.org/10.1111/hir.12233. This article may be used for non-commercial purposes in accordance with Wiley Terms and Conditions for Use of Self-Archived Versions. 
Adler-Milstein, J., DesRoches, C. M., Furukawa, M. F., Worzala, C., Charles, D., Kralovec, P., ... \& Jha, A. K. (2014). More than half of US hospitals have at least a basic EHR, but stage 2 criteria remain challenging for most. Health Affairs, 33(9), 1664-1671.

Ahern, D. K., Woods, S. S., Lightowler, M. C., Finley, S. W., \& Houston, T. K. (2011). Promise of and potential for patient-facing technologies to enable meaningful use. American journal of preventive medicine, 40(5), S162-S172.

Ajami, S., \& Bagheri-Tadi, T. (2013). Barriers for adopting electronic health records (EHRs) by physicians. Acta Informatica Medica, 21(2), 129.

Basden, A. (2002). The critical theory of Herman Dooyeweerd?. Journal of Information Technology, 17(4), 257-269.

Basden, A. (2010). On using spheres of meaning to define and dignify the IS discipline. International Journal of Information Management, 30(1), 13-20.

Basden, A. (2011). Enabling a Kleinian integration of interpretivist and socio-critical IS research: The contribution of Dooyeweerd's philosophy. European Journal of Information Systems, 20(4), 477-489.

Basden, A. (2017). The Foundations of Information Systems: Research and Practice. Routledge.

Basden, A. (1997, October) Aspects of Reality - The Dooyeweerd Pages. Retrieved from http://kgsvr.net/dooy/aspects.html.

Basden, A., \& Burke, M. E. (2004). Towards a philosophical understanding of documentation: a Dooyeweerdian framework. Journal of Documentation, 60(4), 352-370.

Basden, A., \& Wood- Harper, A. T. (2006). A philosophical discussion of the root definition in soft systems thinking: an enrichment of CATWOE. Systems Research and Behavioral Science, 23(1), 61-87.

Bates, D. W., \& Bitton, A. (2010). The future of health information technology in the patient-centered medical home. Health affairs, 29(4), 614-621.

Benbasat, I., \& Weber, R. (1996). Research commentary: Rethinking “diversity” in information systems research. Information systems research, 7(4), 389-399.

Boulus-Rødje, N. (2013, October). Imagined Potentialities of Technologies. In Proceedings of the Annual Conference of CAIS/Actes du congrès annuel de l'ACSI.

37

This is the peer reviewed version of the following article: JONEIDY, S. AND BURKE, M. (2018), TOWARDS A DEEPER UNDERSTANDING OF MEANINGFUL USE IN ELECTRONIC HEALTH RECORDS. HEALTH INFO LIBR J., which has been published in final form at https://doi.org/10.1111/hir.12233. This article may be used for non-commercial purposes in accordance with Wiley Terms and Conditions for Use of Self-Archived Versions. 
Bowens, F. M., Frye, P. A., \& Jones, W. A. (2010). Health information technology: integration of clinical workflow into meaningful use of electronic health records. Perspectives in Health Information Management/AHIMA, American Health Information Management Association, 7(Fall).

Chiasson, M. W., \& Davidson, E. (2004). Pushing the contextual envelope: developing and diffusing IS theory for health information systems research. Information and Organization, 14(3), 155-188.

Choi, Y. J. (2006). Dialogue and antithesis: a philosophical study on the significance of Herman Dooyeweerd's transcendental critique (Vol. 2). The Hermit Kingdom Press.

Clarke, M. A., Belden, J. L., Koopman, R. J., Steege, L. M., Moore, J. L., Canfield, S. M., \& Kim, M. S. (2013). Information needs and information- seeking behaviour analysis of primary care physicians and nurses: a literature review. Health Information \& Libraries Journal, 30(3), 178-190.

Corbett, M., Deardorff, A., \& Kovar-Gough, I. (2014). Emerging data management roles for health librarians in electronic medical records. Journal of the Canadian Health Libraries Association/Journal de l'Association des bibliothèques de la santé du Canada, 35(2), 55-59.

Cox, J. S., \& Srinivasan, R. (2017). Cognitive Mapping and Validation of Medical Codes Across Medical Systems, International Business Machines Corp, U.S. Patent Application No. 15/045,944.

De Raadt, J. D. R. (1995). Expanding the horizon of information systems design. Systems Research and Behavioral Science, 12(3), 185-199.

DesRoches, C. M., Worzala, C., Joshi, M. S., Kralovec, P. D., \& Jha, A. K. (2012). Small, nonteaching, and rural hospitals continue to be slow in adopting electronic health record systems. Health Affairs, 31(5), 1092-1099.

Diller, A. (1990). Herman Dooyeweerd: A Profile of his Thought. Spectrum, 22(2), 139-154.

Dooyeweerd, H. (1955). A New Critique of Theoretical Thought. Vol. I-IV, Ontario: Paideia Press. Falconer, D.J. and D.R. Mackay (1999). "Ontological problems of pluralist research methodologies" Americas Conference on Information Systems. Milwaukee, USA, 13-15 August 1999.

Dooyeweerd, H. (1979). Roots of western culture. Toronto: Wedge.

Eriksson, D. M. (2001). Multi- modal investigation of a business process and information system redesign: a post- implementation case study. Systems Research and Behavioral Science, 18(2), 181-196.

This is the peer reviewed version of the following article: JONEIDY, S. AND BURKE, M. (2018), TOWARDS A DEEPER UNDERSTANDING OF MEANINGFUL USE IN ELECTRONIC HEALTH RECORDS. HEALTH INFO LIBR J., which has been published in final form at https://doi.org/10.1111/hir.12233. This article may be used for non-commercial purposes in accordance with Wiley Terms and Conditions for Use of Self-Archived Versions. 
Franczak, M. J., Klein, M., Raslau, F., Bergholte, J., Mark, L. P., \& Ulmer, J. L. (2014). In emergency departments, radiologists' access to EHRs may influence interpretations and medical management. Health Affairs, 33(5), 800-806.

Halamka, J. D. (2010). Making the most of federal health information technology regulations. Health Affairs, 29(4), 596-600.

Harle, C. A., Gruber, L. A., \& Dewar, M. A. (2014). Factors in medical student beliefs about electronic health record use. Perspectives in health information management, 11(Winter).

Hogan, S. O., \& Kissam, S. M. (2010). Measuring meaningful use. Health Affairs, 29(4), 601-606.

Holden, R. J., \& Karsh, B. T. (2010). The technology acceptance model: its past and its future in health care. Journal of biomedical informatics, 43(1), 159-172.

Hsiao, C. J., Decker, S. L., Hing, E., \& Sisk, J. E. (2012). Most physicians were eligible for federal incentives in 2011, but few had EHR systems that met meaningful-use criteria. Health Affairs, 31(5), 11001107.

Jha, A. K. (2012). Health information technology comes of age: comment on "Achieving meaningful use of health information technology". Archives of internal medicine, 172(9), 737-738.

Jha, A. K., DesRoches, C. M., Campbell, E. G., Donelan, K., Rao, S. R., Ferris, T. G., ... \& Blumenthal, D. (2009). Use of electronic health records in US hospitals. New England Journal of Medicine, 360(16), 16281638.

Kane, S. C. (2006). Multi-aspectual interview technique (Doctoral dissertation, PhD Thesis, University of Salford, UK).

Kazley, A. S., Diana, M. L., Ford, E. W., \& Menachemi, N. (2012). Is electronic health record use associated with patient satisfaction in hospitals?. Health care management review, 37(1), 23-30.

Klecun, E. (2016). Transforming healthcare: policy discourses of IT and patient-centred care. European Journal of Information Systems, 25(1), 64-76.

Krist, A. H., \& Woolf, S. H. (2011). A vision for patient-centered health information systems. Jama, 305(3), 300-301.

39

This is the peer reviewed version of the following article: JONEIDY, S. AND BURKE, M. (2018), TOWARDS A DEEPER UNDERSTANDING OF MEANINGFUL USE IN ELECTRONIC HEALTH RECORDS. HEALTH INFO LIBR J., which has been published in final form at https://doi.org/10.1111/hir.12233. This article may be used for non-commercial purposes in accordance with Wiley Terms and Conditions for Use of Self-Archived Versions. 
Kruse, C. S., Kristof, C., Jones, B., Mitchell, E., \& Martinez, A. (2016). Barriers to electronic health record adoption: a systematic literature review. Journal of medical systems, 40(12), 252.

Lanham, H. J., Leykum, L. K., \& McDaniel Jr, R. R. (2011). Same organization, same electronic health records (EHRs) system, different use: exploring the linkage between practice member communication patterns and EHR use patterns in an ambulatory care setting. Journal of the American Medical Informatics Association, 19(3), 382-391.

Medical Library Association. (2007). Competencies for lifelong learning and professional success: The educational policy statement of the Medical Library Association. Retrieved December, 2, 2009.

Meigs, S. L., \& Solomon, M. (2016). Electronic health record use a bitter pill for many physicians. Perspectives in health information management, 13(Winter).

Mirijamdotter, A., \& Bergvall-Kåreborn, B. (2006). An appreciative critique and refinement of Checkland's soft systems methodology. In In Search of an Integrative Vision for Technology (pp. 79-102). Springer, Boston, MA.

Morton, M. E., \& Wiedenbeck, S. (2010). EHR acceptance factors in ambulatory care: a survey of physician perceptions. Perspectives in Health Information Management/AHIMA, American Health Information Management Association, 7(Winter).

Poon, E. G., Keohane, C. A., Yoon, C. S., Ditmore, M., Bane, A., Levtzion-Korach, O., ... \& Churchill, W. W. (2010). Effect of bar-code technology on the safety of medication administration. New England Journal of Medicine, 362(18), 1698-1707.

Ralston, J. D., Coleman, K., Reid, R. J., Handley, M. R., \& Larson, E. B. (2010). Patient experience should be part of meaningful-use criteria. Health Affairs, 29(4), 607-613.

Sakai, Y. (2013). The role of readability in effective health communication: An experiment using a Japanese health information text on chronic suppurative otitis media. Health Information \& Libraries Journal, 30(3), 220-231.

Serenko, A., Bontis, N., \& Hull, E. (2011). Practical relevance of knowledge management and intellectual capital scholarly research: books as knowledge translation agents. Knowledge and Process Management, $18(1), 1-9$.

\section{0}

This is the peer reviewed version of the following article: JONEIDY, S. AND BURKE, M. (2018), TOWARDS A DEEPER UNDERSTANDING OF MEANINGFUL USE IN ELECTRONIC HEALTH RECORDS. HEALTH INFO LIBR J., which has been published in final form at https://doi.org/10.1111/hir.12233. This article may be used for non-commercial purposes in accordance with Wiley Terms and Conditions for Use of Self-Archived Versions. 
Sinsky, C., Colligan, L., Li, L., Prgomet, M., Reynolds, S., Goeders, L., ... \& Blike, G. (2016). Allocation of physician time in ambulatory practice: a time and motion study in 4 specialties. Annals of internal medicine, 165(11), 753-760.

Spyropoulos, A. C., Viscusi, A., Singhal, N., Gilleylen, J., Kouides, P., Howard, M., ... \& Triller, D. M. (2015). Features of electronic health records necessary for the delivery of optimized anticoagulant therapy: consensus of the ehr task force of the new york state anticoagulation coalition. Annals of Pharmacotherapy, $49(1), 113-124$.

Vessey, I., Ramesh, V., \& Glass, R. L. (2002). Research in information systems: An empirical study of diversity in the discipline and its journals. Journal of Management Information Systems, 19(2), 129-174.

Walker, D. M., \& Diana, M. L. (2016). Hospital adoption of health information technology to support public health infrastructure. Journal of Public Health Management and Practice, 22(2), 175-181.

Winfield, M. J. (2000). Multi-aspectual knowledge elicitation (Doctoral dissertation, Salford: University of Salford).

Wolf, L., Harvell, J., \& Jha, A. K. (2012). Hospitals ineligible for federal meaningful-use incentives have dismally low rates of adoption of electronic health records. Health Affairs, 31(3), 505-513.

41

This is the peer reviewed version of the following article: JONEIDY, S. AND BURKE, M. (2018), TOWARDS A DEEPER UNDERSTANDING OF MEANINGFUL USE IN ELECTRONIC HEALTH RECORDS. HEALTH INFO LIBR J., which has been published in final form at https://doi.org/10.1111/hir.12233. This article may be used for non-commercial purposes in accordance with Wiley Terms and Conditions for Use of Self-Archived Versions. 